\title{
Impact of dietary fiber intake on glycemic control, cardiovascular risk factors and chronic kidney disease in Japanese patients with type 2 diabetes mellitus: the Fukuoka Diabetes Registry
}

Hiroki Fujii', Masanori Iwase ${ }^{1,2^{*}}$, Toshiaki Ohkuma', Shinako Ogata-Kaizu', Hitoshi Ide'1, Yohei Kikuchi', Yasuhiro Idewaki ${ }^{1}$, Tamaki Joudai ${ }^{1}$, Yoichiro Hirakawa ${ }^{3}$, Kazuhiro Uchida ${ }^{4}$, Satoshi Sasaki ${ }^{5}$, Udai Nakamura $^{1}$ and Takanari Kitazono ${ }^{1}$

\begin{abstract}
Background: Dietary fiber is beneficial for the treatment of type 2 diabetes mellitus, although it is consumed differently in ethnic foods around the world. We investigated the association between dietary fiber intake and obesity, glycemic control, cardiovascular risk factors and chronic kidney disease in Japanese type 2 diabetic patients.

Methods: A total of 4,399 patients were assessed for dietary fiber intake using a brief self-administered diet history questionnaire. The associations between dietary fiber intake and various cardiovascular risk factors were investigated cross-sectionally.

Results: Body mass index, fasting plasma glucose, $\mathrm{HbA1c}$, triglyceride and high-sensitivity C-reactive protein negatively associated with dietary fiber intake after adjusting for age, sex, duration of diabetes, current smoking, current drinking, total energy intake, fat intake, saturated fatty acid intake, leisure-time physical activity and use of oral hypoglycemic agents or insulin. The homeostasis model assessment insulin sensitivity and HDL cholesterol positively associated with dietary fiber intake. Dietary fiber intake was associated with reduced prevalence of abdominal obesity, hypertension and metabolic syndrome after multivariate adjustments including obesity. Furthermore, dietary fiber intake was associated with lower prevalence of albuminuria, low estimated glomerular filtration rate and chronic kidney disease after multivariate adjustments including protein intake. Additional adjustments for obesity, hypertension or metabolic syndrome did not change these associations.
\end{abstract}

Conclusion: We demonstrated that increased dietary fiber intake was associated with better glycemic control and more favorable cardiovascular disease risk factors including chronic kidney disease in Japanese type 2 diabetic patients. Diabetic patients should be encouraged to consume more dietary fiber in daily life.

Keywords: Adiponectin, Albuminuria, Chronic kidney disease, Diabetes mellitus, Dietary fiber, Homeostasis model assessment, Hypertension, Inflammation, Insulin resistance, Metabolic syndrome

\footnotetext{
* Correspondence: iwase@intmed2.med.kyushu-u.ac.jp

${ }^{1}$ Department of Medicine and Clinical Science, Graduate School of Medical

Sciences, Kyushu University, Maidashi 3-1-1, Higashi-ku, Fukuoka 812-8582,

Japan

${ }^{2}$ Diabetes Centre, Hakujyuji Hospital, Fukuoka, Japan

Full list of author information is available at the end of the article
} 


\section{Background}

Diet rich in dietary fiber is beneficial for the treatment of type 2 diabetes mellitus [1], as dietary fiber ameliorates postprandial hyperglycemia by delaying digestion and absorption of carbohydrates and enhances satiety, which leads to a reduction in body weight [2]. In insulin-resistant subjects, dietary fiber may enhance peripheral insulin sensitivity possibly via short-chain fatty acids produced by fermentation of fiber in the intestines [3-5]. The hypoglycemic actions of dietary fiber in type 2 diabetic patients have been investigated by conducting interventions with high fiber diets or supplements [2]. In addition, an epidemiologic study [6] recently reported that HbA1c was significantly lower in type 2 diabetic patients with high fiber intake than in those with low fiber intake among 934 Chinese subjects who ate foods containing larger amounts of fiber than the Western diet [7].

As for cardiovascular disease (CVD) risk factors in type 2 diabetic patients, the effects of dietary fiber were not fully explored. Soluble fiber forms gels in the gastrointestinal tract, and may decrease the absorption of glucose and cholesterol from the intestinal lumen [8]. High fiber diet improved diabetic dyslipidemia in some studies [9], and a low fiber intake was associated with metabolic syndrome in Brazilian type 2 diabetic patients [10]. Although the consumption of whole grains rich in insoluble fiber was reported not to be associated with improvements in glycemic control $[9,11]$, it suppressed low-grade systemic inflammation [12] and was inversely associated with allcause and CVD-specific mortality among diabetic females in the Nurses' Health Study [13]. Recently, it was reported that increased dietary fiber, especially soluble fiber intake was associated with reduced all-cause and CVD-specific mortality in type 1 diabetic patients [14]. However, a recent review reported that adding fiber supplements in moderate amounts (4-19 g) to daily diet leads to little improvement in glycemic or CVD risk markers, although the effects of dietary fiber were investigated mostly in subjects consuming Western diet [9]. Dietary fiber is consumed differently in ethnic foods around the world, and the protective effects of dietary fiber on the development of diabetes differed by ethnic group according to consumed foods [15]. Japanese foods consist of dietary fiber primarily in the form of vegetables including seaweed, and contain smaller amounts of fiber than Western diet, of which the main source of fiber is whole grains $[7,16]$. It has been reported that increased intake of dietary fiber is associated with reduced mortality from CVD in the Japanese general population $[17,18]$, although the effects of dietary fiber intake have not been investigated in diabetic patients. In the present study, we investigated the associations of dietary fiber intake with glycemic control and CVD risk factors, i.e., metabolic syndrome, LDL cholesterol, low-grade inflammation and chronic kidney disease (CKD) in Japanese type 2 diabetic patients. This cross-sectional study suggested the beneficial effects of dietary fiber on glycemia and a wide range of CVD risk factors including CKD.

\section{Methods \\ Subjects}

The Fukuoka Diabetes Registry is a multicenter prospective study designed to investigate the effects of modern treatment on the prognosis of diabetic patients attending teaching hospitals certified by the Japan Diabetes Society or certified diabetes clinics in Fukuoka Prefecture, Japan (UMIN Clinical Trial Registry 000002627) [19]. A total of 5,131 diabetic patients 20 years of age or older were registered between April 2008 and October 2010. After excluding 261 subjects with type 1 diabetes mellitus, 468 subjects who had already eaten breakfast and three subjects who reported consuming less than $500 \mathrm{kcal}$ in a dietary survey, the remaining 4,399 subjects (2,493 males, 1,906 females) were enrolled in this cross-sectional study. The exclusion criteria were: 1) patients with drug-induced diabetes and those receiving steroid treatment, 2) patients under renal replacement therapy and 3) patients with serious diseases other than diabetes, such as advanced malignancy, decompensated liver cirrhosis, etc. and 4) patients unable to visit diabetologists regularly. This study was conducted with the approval of the Kyushu University Institutional Review Board, and written informed consent was obtained from all participants.

\section{Dietary assessment}

The dietary survey was conducted using a brief selfadministered diet history questionnaire (BDHQ) to assess the subjects' dietary intake during the preceding month. The BDHQ includes 58 foods and beverage items. The subjects indicated their mean frequency of consumption in terms of the specified serving size by checking one of seven frequency categories ranging from "almost never" to "two or more times a day" [20]. The dietary intake estimates for total energy and several nutrients, including dietary fiber, were calculated using an ad hoc algorithm developed for the BDHQ based on the Standard Tables of Food Composition in Japan [21]. Validation of ranking energy-adjusted fiber intake has been previously studied in an adult Japanese population [22]. The correlation coefficient of dietary fiber intake between semi-weighed dietary records for 16 days and BDHQ was 0.66 in females $(\mathrm{n}=92)$ and 0.70 in males $(\mathrm{n}=92)$, respectively.

\section{Clinical evaluation}

Participants completed a self-administered questionnaire concerning the duration of diabetes mellitus, alcohol intake, smoking habits and physical activity. Body mass index (BMI) was calculated from each subject's height and weight, 
and obesity was defined as BMI of $\geq 25 \mathrm{~kg} / \mathrm{m}^{2}$ according to Japan Society for the Study of Obesity [23]. Waist circumference at the umbilical level was measured by a trained staff member with the subject in the standing position, and blood pressure was measured with the subject in the sitting position. The subjects' medical records were reviewed for oral hypoglycemic agent and insulin use. Leisure time physical activity information was obtained using a self-reported questionnaire, and metabolic equivalent (met) hours per week was calculated using Ainsworth's methods [24].

\section{Laboratory measurements}

Blood was collected via venipuncture. Spot urine samples were obtained, and the assessments were performed at one central laboratory. HbA1c was determined using high-performance liquid chromatography (Tosoh Corp., Tokyo, Japan), plasma glucose by glucose oxidase method, serum C-peptide by chemiluminescent immunoassay (Kyowa Medex, Tokyo, Japan), serum adiponectin and high sensitivity C-reactive protein (HS-CRP) by latex immunonephelometry (Mitsubishi Chemical Medience, Tokyo, Japan; Siemens Healthcare Diagnostics, Tokyo, Japan), urinary albumin by immunonephelometry (Medical and Biological Laboratories, Nagoya, Japan) and serum total cholesterol, LDL cholesterol, HDL cholesterol, triglyceride, creatinine and urine creatinine by enzymatic methods. Estimated glomerular filtration rate (eGFR) was calculated using the equation proposed by the Japanese Society of Nephrology [25]. $\beta$ cell function and insulin sensitivity were estimated based on fasting glucose and $\mathrm{C}$-peptide concentrations using the HOMA Calculator, version 2.2.2 [http://www.dtu.ox.ac.uk, accessed June 2012], and expressed as the homeostasis model assessment $\beta$ cell function (HOMA2-\%B) and the homeostasis model assessment insulin sensitivity (HOMA2-\%S), respectively. A total of 587 participants with unacceptable levels of plasma glucose $(<3 \mathrm{mmol} / \mathrm{l}$ or $>25 \mathrm{mmol} / \mathrm{l})$ or C-peptide $(<0.2 \mathrm{nmol} / \mathrm{l}$ or $>3.5 \mathrm{nmol} / \mathrm{l})$ were excluded [26]. Albuminuria was defined as urinary albumin excretion $\geq 30 \mathrm{mg} / \mathrm{gCr}$, and CKD was defined as albuminuria and/or eGFR $<60 \mathrm{ml} /$ $\mathrm{min} / 1.73 \mathrm{~m}^{2}$ [27]. Metabolic syndrome was defined according to the definition of "Harmonizing the Metabolic Syndrome" [28], i.e., the presence of at least two of the following four components: central obesity for Asians (waist circumference $\geq 90 \mathrm{~cm}$ in males and $\geq 80 \mathrm{~cm}$ in females), elevated triglycerides $(\geq 1.69 \mathrm{mmol} / \mathrm{l}$ and/or the use of triglyceride-lowering drugs), reduced HDL cholesterol $(<1.03 \mathrm{mmo} / \mathrm{l}$ in males and $<1.29 \mathrm{mmol} / \mathrm{l}$ in females) and elevated blood pressure (systolic blood pressure $\geq 130 \mathrm{mmHg}$ and/or diastolic blood pressure $\geq 85 \mathrm{mmHg}$ and/or the use of antihypertensive drugs). The presence of depressive symptoms was assessed using the Center for Epidemiologic Studies Depression
Scale [29], and subjects who scored more than 16 out of 60 points were defined as having depressive symptoms.

\section{Statistical analysis}

The correlations with dietary fiber intake were assessed by Pearson's correlation for continuous variables and a logistic regression analysis for categorical variables. The regression coefficients and 95\% CIs' were calculated using a multiple regression analysis after multivariate adjustment for potential confounding factors, including age, sex, duration of diabetes, current smoking habits, current drinking habits, total energy intake, fat intake, saturated fatty acid intake, protein intake (only for urinary albumin excretion and eGFR), leisure time physical activity and use of oral hypoglycemic agents or insulin. Due to their skewed distributions, triglyceride, adiponectin and urinary albumin excretion values were log transformed, and the results were expressed as geometric means with $95 \%$ CIs. The multivariateadjusted ORs and 95\% CIs for metabolic syndrome and chronic kidney disease were calculated using a multiple logistic regression model. All statistical analyses were performed using the SAS software package version 9.3 (SAS Institute Inc., Cary, NC). Values of $\mathrm{P}<0.05$ were considered to be statistically significant in all of the analyses.

\section{Results}

Table 1 shows the clinical characteristics of the studied participants and correlations with dietary fiber intake. Regarding the source of dietary fiber, vegetables were most frequently eaten, followed by cereals, legumes and beans and fruits, as reported previously in the general population in Japan [16]. Age, fat and protein intakes and leisure time physical activity were positively associated with dietary fiber intake. The proportions of males, current smokers, current drinkers, saturated fatty acid intake and the proportion of participants with depressive symptoms were negatively associated with dietary fiber intake. However, the duration of diabetes and treatment for diabetes were not associated with dietary fiber intake.

As shown in Table 2, BMI, waist circumference, fasting plasma glucose (FPG), HbA1c, fasting serum C-peptide, HS-CRP, triglyceride, systolic blood pressure and urinary albumin excretion were significantly and negatively associated with dietary fiber intake after adjusting for age, sex, duration of diabetes, current smoking habits, current drinking habits, total energy intake, fat intake, saturated fatty acid intake, protein intake (only for urinary albumin excretion), leisure time physical activity and use of oral hypoglycemic agents or insulin. The insulin sensitivity index HOMA2\%-S, HDL cholesterol and eGFR were significantly and positively associated with dietary fiber intake after multivariate adjustments including protein intake (only for eGFR). The insulin secretion index HOMA2\%-B, adiponectin, total cholesterol, LDL cholesterol and diastolic blood 
Table 1 Characteristics of the studied participants and correlations with dietary fiber intake

\begin{tabular}{|c|c|c|c|}
\hline & Mean or percentage & Correlation coefficient or odds ratio & $\mathrm{p}$ \\
\hline Number & 4,399 & & \\
\hline Dietary fiber intake (g/1,000 kcal) & $7.60 \pm 0.03$ & - & \\
\hline Fiber from vegetables (\%) & $47.1 \pm 0.2$ & $0.42^{*}$ & $<0.0001$ \\
\hline Fiber from cereals (\%) & $22.5 \pm 0.2$ & $-0.60^{*}$ & $<0.0001$ \\
\hline Fiber from legumes and beans (\%) & $11.8 \pm 0.1$ & $0.11^{*}$ & $<0.0001$ \\
\hline Fiber from fruits (\%) & $9.5 \pm 0.1$ & $0.15^{*}$ & $<0.0001$ \\
\hline Age (years) & $65.4 \pm 0.2$ & $0.18^{*}$ & $<0.0001$ \\
\hline Sex (male, \%) & 56.7 & $0.76[0.74-0.78]^{\#}$ & $<0.0001$ \\
\hline Duration of diabetes (years) & $15.5 \pm 0.2$ & $0.00^{*}$ & ns \\
\hline Current smoker (\%) & 18.3 & $0.79[0.76-0.82]^{\#}$ & $<0.0001$ \\
\hline Current drinker (\%) & 38.8 & $0.77[0.74-0.79]^{\#}$ & $<0.0001$ \\
\hline Total energy intake (kcal) & $1689 \pm 7$ & $-0.12^{*}$ & $<0.0001$ \\
\hline Fat intake (g/day) & $52.4 \pm 0.3$ & $0.09^{*}$ & $<0.0001$ \\
\hline Saturated fatty acid intake (g/day) & $12.3 \pm 0.1$ & $-0.08^{*}$ & $<0.0001$ \\
\hline Protein intake (g/day) & $67.3 \pm 0.4$ & $0.04^{*}$ & 0.006 \\
\hline Leisure-time physical activity (met $\cdot$ hr/week) & $11.8 \pm 0.2$ & $0.12^{*}$ & $<0.0001$ \\
\hline Depressive symptoms (\%) & 8.9 & $0.95[0.90-0.99]^{\#}$ & 0.035 \\
\hline Oral hypoglycemic agents (\%) & 64.1 & $0.99[0.96-1.01]^{\#}$ & ns \\
\hline Insulin therapy (\%) & 27.1 & $0.98[0.95-1.01]^{\#}$ & ns \\
\hline
\end{tabular}

Mean \pm SE. * correlation coefficient, " odds ratio with $95 \% \mathrm{Cl}$.

Table 2 Multiple regression analysis of dietary fiber intake with clinical and laboratory variables

\begin{tabular}{|c|c|c|c|}
\hline Variables & Mean & Regression coefficient & $p$ for trend \\
\hline Body mass index $\left(\mathrm{kg} / \mathrm{m}^{2}\right)$ & $23.8 \pm 0.06$ & $-0.18[-0.24,-0.11]$ & $<0.0001$ \\
\hline Waist circumference $(\mathrm{cm})$ & $85.9 \pm 0.2$ & $-0.56[-0.73,-0.39]$ & $<0.0001$ \\
\hline Fasting plasma glucose (mmol/l) & $7.73 \pm 0.03$ & $-0.049[-0.084,-0.014]$ & 0.007 \\
\hline $\mathrm{HbA1c}(\%)$ & $7.42 \pm 0.02$ & $-0.022[-0.038,-0.005]$ & 0.009 \\
\hline $\mathrm{HbA} 1 \mathrm{c}(\mathrm{mmol} / \mathrm{mol})$ & $57.6 \pm 0.2$ & $-0.24[-0.42,-0.06]$ & 0.009 \\
\hline Fasting serum C-peptide (nmol/l) & $0.402 \pm 0.003$ & $-0.009[-0.013,-0.006]$ & $<0.0001$ \\
\hline HOMA2\%-B & $45.7 \pm 0.4$ & $-0.26[-0.68,0.17]$ & ns \\
\hline HOMA2\%-S & $106.0 \pm 0.6$ & $1.95[1.27,2.62]$ & $<0.0001$ \\
\hline Adiponectin $(\mu \mathrm{g} / \mathrm{ml})^{*}$ & $9.1[8.9-9.2]$ & $0.006[-0.003,0.016]$ & ns \\
\hline $\mathrm{HS}-\mathrm{CRP}(\mathrm{mg} / \mathrm{l})^{*}$ & $0.50[0.48-0.52]$ & $-0.067[-0.090,-0.043]$ & $<0.0001$ \\
\hline Total cholesterol (mmol/l) & $4.99 \pm 0.01$ & $0.009[-0.005,0.023]$ & ns \\
\hline LDL cholesterol (mmol/l) & $2.87 \pm 0.01$ & $0.010[-0.002,0.022]$ & ns \\
\hline HDL cholesterol (mmol/l) & $1.47 \pm 0.01$ & $0.008[0.001,0.014]$ & 0.017 \\
\hline Triglyceride $(\mathrm{mmol} / \mathrm{l})^{*}$ & $1.22[1.20-1.24]$ & $-0.013[-0.022,-0.005]$ & 0.003 \\
\hline Systolic blood pressure $(\mathrm{mmHg})$ & $130.7 \pm 0.3$ & $-0.35[-0.64,-0.06]$ & 0.017 \\
\hline Diastolic blood pressure $(\mathrm{mmHg})$ & $74.7 \pm 0.2$ & $-0.05[-0.22,0.13]$ & ns \\
\hline Urinary albumin excretion (mg/g) & $28.2[26.8-29.7]$ & $-0.092[-0.121,-0.063]$ & $<0.0001$ \\
\hline eGFR $\left(\mathrm{ml} / \mathrm{min} / 1.73 \mathrm{~m}^{2}\right)$ & $75.0 \pm 0.3$ & $0.34[0.01,0.67]$ & 0.042 \\
\hline
\end{tabular}

Mean \pm SE. *Geometric means with $95 \% \mathrm{Cl}$ in brackets. HOMA2-\%B, homeostasis model assessment $\beta$-cell function; HOMA2-\%S, homeostasis model assessment insulin sensitivity; HS-CRP, high sensitivity-C reactive protein; eGFR, estimated glomerular filtration rate. The multivariate adjustment included age, sex, duration of diabetes, current smoking habits, current drinking habits, total energy intake, fat intake, saturated fatty acid intake, protein intake (only for urinary albumin excretion and eGFR), leisure time physical activity and use of oral hypoglycemic agents or insulin. 
pressure were not significantly associated with dietary fiber intake.

The results of multiple logistic analysis between metabolic syndrome and dietary fiber intake are shown in Table 3. The prevalence of obesity, abdominal obesity, hypertension, hypertriglyceridemia, low HDL cholesterol and metabolic syndrome in the study participants was $31.2 \%, 47.0 \%, 73.9 \%$, $29.2 \%, 18.2 \%$ and $54.5 \%$, respectively. Abdominal obesity and hypertension were negatively associated with dietary fiber intake after multivariate adjustments, and further adjustment with obesity did not change the trends. Hypertriglyceridemia and low HDL cholesterol were not associated with dietary fiber intake. Consequently, metabolic syndrome was negatively associated with dietary fiber intake after multivariate adjustment with additional adjustment for obesity.

The results of multiple logistic analysis between chronic kidney disease and dietary fiber intake are shown in Table 4. The prevalence of albuminuria, low eGFR and chronic kidney disease in the study participants was 38.4\%, 21.5\% and $46.9 \%$, respectively. Albuminuria, low eGFR and CKD were negatively associated with dietary fiber intake after multivariate adjustments. These trends were not significantly affected by additional adjustment for obesity, hypertension or metabolic syndrome.

\section{Discussion}

The present study demonstrated that dietary fiber intake was associated with better glycemic control and more favorable CVD risk factors including abdominal obesity, hypertension and metabolic syndrome, along with enhanced insulin sensitivity and reduced HS-CRP after adjusting for confounding factors. Furthermore, the proportion of participants with CKD negatively associated with dietary fiber intake, even after adjusting for obesity, hypertension or metabolic syndrome. To the best of our knowledge, there are few epidemiological studies showing associations of dietary fiber intake with glycemia and CVD risk factors in Asia, where the epidemic of type 2 diabetes is rapidly becoming a serious medical and socioeconomic issue.

A recent systematic review of the literature reported that adding fiber supplements in moderate amounts (4-19 g) to daily diet achieved little improvement in glycemic control or CVD risk factors [9]. On the other hand, another meta-analysis [2] of intervention trials using high fiber diet (mean increase in fiber $18.3 \mathrm{~g} / \mathrm{d}$ ) in type 2 diabetic patients revealed that FPG and HbA1c were modestly lowered by $0.83 \mathrm{mmol} / \mathrm{l}$ and $0.26 \%$, respectively, compared with a placebo. In the present study, both FPG and HbA1c negatively associated with dietary fiber intake (Table 2). In addition, the insulin sensitivity index HOMA2\%-S and HS-CRP were associated with dietary fiber intake and the association remained statistically significant after the additional adjustment for BMI (regression coefficient 1.34 [0.71, 1.97], -0.048 [-0.070,-0.025], respectively). Although the effects of dietary fiber on insulin sensitivity have not been studied in type 2 diabetic patients, dietary fiber enhances insulin sensitivity in hepatic and peripheral tissues in insulin-resistant obese subjects [3-5].

It was recently reported that the consumption of high fiber diet for four weeks enhanced insulin secretion in nondiabetic overweight subjects [30]. Dietary fiber may activate incretin secretion due to short-chain fatty acid production induced by the fermentation of dietary fiber [31], although, in one study, it took one year for high fiber diet to enhance glucagon-like peptide-1 secretion in healthy subjects [32]. In the present study, the insulin secretion index HOMA2\%-B was not associated with dietary fiber intake, suggesting that it is unlikely that insulin

Table 3 Multiple logistic analysis between metabolic syndrome and dietary fiber intake

\begin{tabular}{|c|c|c|c|}
\hline & & Odds ratio & $p$ for trend \\
\hline \multirow[t]{2}{*}{ Elevated waist circumference } & Model & $0.90[0.87-0.94]$ & $<0.0001$ \\
\hline & Model + obesity & $0.93[0.89-0.97]$ & 0.002 \\
\hline \multirow[t]{2}{*}{ Elevated blood pressure } & Model & 0.93 [0.89-0.97] & 0.0002 \\
\hline & Model + obesity & $0.94[0.91-0.98]$ & 0.006 \\
\hline \multirow[t]{2}{*}{ Elevated triglyceride } & Model & $0.97[0.93-1.00]$ & ns \\
\hline & Model + obesity & $0.98[0.95-1.02]$ & ns \\
\hline \multirow[t]{2}{*}{ Low HDL cholesterol } & Model & $0.97[0.93-1.01]$ & ns \\
\hline & Model + obesity & $0.98[0.93-1.02]$ & ns \\
\hline \multirow[t]{2}{*}{ Metabolic syndrome } & Model & $0.92[0.89-0.96]$ & $<0.0001$ \\
\hline & Model + obesity & $0.95[0.91-0.99]$ & 0.009 \\
\hline
\end{tabular}

Obesity: BMI $\geq 25.0 \mathrm{~kg} / \mathrm{m} 2$; Elevated waist circumference, waist circumference $\geq 90 \mathrm{~cm}$ in males and $\geq 80 \mathrm{~cm}$ in females; Elevated blood pressure, systolic blood pressure $\geq 130 \mathrm{mmHg}$ and/or diastolic blood pressure $\geq 85 \mathrm{mmHg}$ and/or the use of antihypertensive drugs; Elevated triglyceride, fasting serum triglyceride $\geq 1.69 \mathrm{mmol} / \mathrm{l}$ and/or the use of triglyceride-lowering drugs; Low HDL cholesterol, fasting serum $\mathrm{HDL}$ cholesterol $<1.03 \mathrm{mmol} / \mathrm{l}$ in males and $<1.29 \mathrm{mmol} / \mathrm{l}$ in females. Metabolic syndrome was defined according to the definition of "Harmonizing the Metabolic Syndrome." Model, multivariate adjustments with age, sex, duration of diabetes, current smoking habits, current drinking habits, total energy intake, fat intake, saturated fatty acid intake, leisure time physical activity and use of oral hypoglycemic agents or insulin. 
Table 4 Multiple logistic analysis between chronic kidney disease and dietary fiber intake

\begin{tabular}{|c|c|c|c|}
\hline & & Odds ratio & $\mathrm{p}$ for trend \\
\hline \multirow[t]{4}{*}{ Albuminuria $\geq 30 \mathrm{mg} / \mathrm{g}$} & Model & $0.92[0.88-0.95]$ & $<0.0001$ \\
\hline & Model + obesity & $0.93[0.89-0.96]$ & $<0.0001$ \\
\hline & Model + elevated blood pressure & $0.93[0.89-0.96]$ & $<0.0001$ \\
\hline & Model + metabolic syndrome & $0.93[0.89-0.96]$ & $<0.0001$ \\
\hline \multirow[t]{4}{*}{$\mathrm{eGFR}<60 \mathrm{ml} / \mathrm{min} / 1.73 \mathrm{~m}^{2}$} & Model & $0.94[0.90-0.98]$ & 0.006 \\
\hline & Model + obesity & $0.95[0.90-0.99]$ & 0.015 \\
\hline & Model + elevated blood pressure & $0.95[0.91-0.99]$ & 0.019 \\
\hline & Model + metabolic syndrome & $0.95[0.91-0.99]$ & 0.027 \\
\hline \multirow[t]{4}{*}{ Chronic kidney disease } & Model & $0.93[0.90-0.96]$ & $<0.0001$ \\
\hline & Model + obesity & $0.94[0.90-0.97]$ & 0.0005 \\
\hline & Model + elevated blood pressure & $0.94[0.91-0.97]$ & 0.0009 \\
\hline & Model + metabolic syndrome & $0.94[0.91-0.98]$ & 0.0011 \\
\hline
\end{tabular}

Obesity: $\mathrm{BMI} \geq 25.0 \mathrm{~kg} / \mathrm{m} 2$; Elevated waist circumference, waist circumference $\geq 90 \mathrm{~cm}$ in males and $\geq 80 \mathrm{~cm}$ in females; Elevated blood pressure, systolic blood pressure $\geq 130 \mathrm{mmHg}$ and/or diastolic blood pressure $\geq 85 \mathrm{mmHg}$ and/or the use of antihypertensive drugs; Elevated triglyceride, fasting serum triglyceride $\geq 1.69 \mathrm{mmol} / \mathrm{l}$ and/or the use of triglyceride-lowering drugs; Low HDL cholesterol, fasting serum HDL cholesterol $<1.03 \mathrm{mmol} / \mathrm{l}$ in males and $<1.29 \mathrm{mmol} / \mathrm{l}$ in females. Metabolic syndrome was defined according to the definition of "Harmonizing the Metabolic Syndrome." Model, multivariate adjustments with age, sex, duration of diabetes, current smoking habits, current drinking habits, total energy intake, fat intake, saturated fatty acid intake, protein intake, leisure time physical activity and use of oral hypoglycemic agents or insulin.

secretion induced by increased dietary fiber intake contributes to improving hyperglycemia.

In general, dietary fiber favorably affects CVD risk factors, including LDL cholesterol [33] and components of metabolic syndrome [34,35]. In type 2 diabetic patients, a recent review reported that high fiber diet failed to affect the lipid levels in four out of eight randomized controlled studies [9]. In the present study, total cholesterol and LDL cholesterol were not associated with dietary fiber intake. However, HDL cholesterol and triglyceride were significantly associated with dietary fiber intake. Dietary fiber exerts blood pressure-lowering effects [36,37], and recently, Jenkins et al. [38] reported that high fiber and low glycemic index diet with legumes reduced blood pressure compared with wheat fiber diet in type 2 diabetic patients. In the present study, systolic blood pressure and hypertension were negatively associated with dietary fiber intake. Enhanced insulin sensitivity may contribute to the blood pressure-lowering effects of dietary fiber. As a result, the prevalence of metabolic syndrome was significantly associated with dietary fiber intake. Reduced fiber intake, particularly at breakfast, was found to be associated with metabolic syndrome in Brazilian type 2 diabetic patients $[10,39]$, although the authors did not report which component of metabolic syndrome was associated with low fiber intake. The present study demonstrated that dietary fiber intake was associated with reduced prevalence of abdominal obesity and hypertension of metabolic syndrome phenotypes independent of obesity. A reduction in abdominal obesity induced by increased dietary fiber intake has been reported in both intervention $[40,41]$ and epidemiological studies [42]. However, the direct effects of dietary fiber on visceral adipose tissue remain to be elucidated.

CKD is an established CVD risk factor. The present study demonstrated the association between dietary fiber intake and lower prevalence of CKD (Table 4). Due to the crosssectional nature of the study, preventing hyperkalemia in the advanced stage of CKD may limit the consumption of fresh fruits and green vegetables. Indeed, in this study, the proportion of participants with eGFR $<30 \mathrm{ml} / \mathrm{min} /$ $1.73 \mathrm{~m}^{2}$ was negatively associated with dietary fiber intake (odds ratio 0.83 [0.76-0.91]). However, excluding participants with eGFR $<30 \mathrm{ml} / \mathrm{min} / 1.73 \mathrm{~m}^{2}(\mathrm{n}=115) \mathrm{did}$ not change the results (odds ratio 0.94 [0.91-0.97]). CVD risk factors, such as obesity, hypertension and metabolic syndrome, may contribute to the development and progression of CKD. However, adjusting for each CVD risk factor did not change the significant association between dietary fiber intake and CKD (Table 4). Although the mechanisms of action of dietary fiber in the kidneys are unknown, high dietary fiber intake is associated with a lower level of systemic micro-inflammation in both nondiabetic and diabetic patients $[8,12]$, as shown in the present study (Table 2). The anti-inflammatory actions of dietary fiber may be related to reduced prevalence of CKD. Recently, a large follow-up study showed that increased dietary fiber intake was associated with reduced mortality in CKD patients [43]. In this context, dietary fiber appears to be promising non-pharmacological treatment for CKD.

The strength of the present study includes a relatively large sample size of type 2 diabetic patients consuming 
foods different from Western diet [7]. A staple food in the Japanese diet is white rice, which has lower dietary fiber than whole grains. The amount of daily fiber intake in Japan declined from $20.5 \mathrm{~g} / \mathrm{d}$ to $15 \mathrm{~g} / \mathrm{d}$ after World War II [44] to a level that is lower than that observed in the US and UK [7]. The main source of dietary fiber of Japanese people is vegetables including seaweed, a typical Japanese food, followed by cereals, legumes and fruits [16]. The present study showed that the dietary fiber present in Japanese foods exerts beneficial effects on glycemia and CVD risk factors, thus suggesting that the usefulness of increased dietary fiber intake may extend beyond certain ethnic foods. Another strength of the study is that confounding factors included fat and saturated fatty acid intakes and physical activity, since high dietary fiber intake is often associated with healthy lifestyle, making it difficult to isolate fiber effects from general healthy lifestyle [14]. However, some limitations should be discussed. First, the use of a self-administered food frequency dietary assessment questionnaire BDHQ is subject to measurement error in dietary intake, and actual dietary habits may not be obtained. However, the ability to rank dietary fiber using the BDHQ has been reasonably verified [22]. Second, study participants who visit diabetologists regularly may be better educated about self-management of diabetes with respect to diet than the general population. However, the daily fiber intake of the study participants was similar to that of the general population in Japan $(15 \mathrm{~g} / \mathrm{d})$. Third, since multiple outcomes were involved in the present study, multiple testing may induce false results. Finally, we cannot prove cause-and-effect relationships due to the cross-sectional design of our study, and there may be other confounding factors in addition to those evaluated in the present study.

\section{Conclusion}

We demonstrated that increased dietary fiber intake was associated with better glycemic control and more favorable CVD risk factors including hypertension, metabolic syndrome and CKD, along with improvements in insulin sensitivity and micro-inflammation, in Japanese type 2 diabetic patients after adjusting for confounding factors. Although the recommended amount of dietary fiber in the general population is $>19 \mathrm{~g} / \mathrm{d}$ for males and $>17 \mathrm{~g} / \mathrm{d}$ for females in Japan [45] and $>38 \mathrm{~g} / \mathrm{d}$ for males and $>25 \mathrm{~g} / \mathrm{d}$ for females in the US [46], diabetic patients should be encouraged to consume more dietary fiber in daily life according to the ethnic foods.

\section{Abbreviations}

BDHQ: Brief-type self-administered diet history questionnaire; BMl: Body mass index; CKD: Chronic kidney disease; CVD: Cardiovascular disease; eGFR: Estimated glomerular filtration rate; FPG: Fasting plasma glucose; HS-CRP: High sensitivity C-reactive protein; HOMA2-\%B: Homeostasis model assessment $\beta$ cell function; HOMA2-\%S: Chomeostasis model assessment insulin sensitivity.

\section{Competing interests}

The authors declare that they have no competing interests.

\section{Authors' contributions}

$\mathrm{HF}$ and $\mathrm{MI}$ were responsible for the study concept and design. $\mathrm{HF}$ and $\mathrm{Ml}$ conducted the analyses, and TO, SO, HI, YK, YI, TJ, YH, KU, SS, UN and TK helped with interpreting the data and contributed to the discussion. HF and $\mathrm{Ml}$ drafted the manuscript. All authors participated in revising the manuscript critically and approved the final version.

\section{Acknowledgements}

We thank Y. Kiyohara, T. Ninomiya, Y. Doi, S. Kanba, D. Kang, S. Kumagai, H. Kishimoto (Kyushu University), T. Shirota (Nakamura Gakuen University), N. Tsutsu, N. Sasaki, S. Nohara, C.Miyagawa, Y. Komorida (Fukuoka Red Cross Hospital), K. Nunoi, Y. Sato, H. Imoto, M. Toyonaga, A. Yamauchi, C. Matsumoto (St Mary's Hospital), K. Amano, K. Itoh (Steel Memorial Yawata Hospital), D. Gotoh, T. Himeno, C. Sejima (Kyushu Central Hospital), N. Shinohara, A. Tsutsumi, A. Sumi (Fukuoka Higashi Medical Centre), M. Nakano, M. Matsuo, S. Morimoto, T. Hyodo (Hakujyuji Hospital), M. Minami (Clinic Minami Masae), M. Wada (Wada Miya Naika Clinic), Y. Yokomizo (Yokomizo Naika Clinic), M. Kikuchi (Kikuchi Naika Clinic), R. Nomiyama (Suzuki Naika Clinic), S. Nakamura (Nakamura Naika Clinic), K. Tashiro (Oshima Eye Hospital), M. Yoshinari (Yoshinari Naika Clinic), K. Ichikawa (Fukutsu Naika Clinic) and T. Omae (Hisayama Research Institute for Lifestyle Diseases) in addition to clinical research coordinators C. Ohba, Y. Ono and K. Sekioka and administrative staff T. Matake and J. Ishimatsu. We thank B. Quinn for editing our manuscript (Japan Medical Communication).

\section{Grant support}

This work was supported in part by JSPS KAKENHI (grant number 23249037, 23659353) for MI.

\section{Author details}

'Department of Medicine and Clinical Science, Graduate School of Medical Sciences, Kyushu University, Maidashi 3-1-1, Higashi-ku, Fukuoka 812-8582, Japan. ${ }^{2}$ Diabetes Centre, Hakujyuji Hospital, Fukuoka, Japan. ${ }^{3}$ Department of Environmental Medicine, Graduate School of Medical Sciences, Kyushu University, Fukuoka, Japan. ${ }^{4}$ Department of Health Promotion, School of Health and Nutrition Science, Nakamura, Gakuen University, Fukuoka, Japan. ${ }^{5}$ Department of Social and Preventive Epidemiology, School of Public Health, The University of Tokyo, Tokyo, Japan.

Received: 14 August 2013 Accepted: 6 December 2013 Published: 11 December 2013

\section{References}

1. American Diabetes Association: Standards of medical care in diabetes-2013. Diabetes Care 2013, 36(Suppl 1):S11-S66.

2. Post RE, Mainous AG III, King DE, Simpson KN: Dietary fiber for the treatment of type 2 diabetes mellitus: a meta-analysis. J Am Board Fam Med 2012, 25:16-23.

3. Johnston KL, Thomas EL, Bell JD, Frost GS, Robertson MD: Resistant starch improves insulin sensitivity in metabolic syndrome. Diabet Med 2010, 27:391-397.

4. Robertson MD, Wright JW, Loizon E, Debard C, Vidal H, Shojaee-Moradie F, Russell-Jones D, Umpleby AM: Insulin-sensitizing effects on muscle and adipose tissue after dietary fiber intake in men and women with metabolic syndrome. J Clin Endocrinol Metab 2012, 97:3326-3332.

5. Weickert MO, Mohlig M, Schofl C, Arafat AM, Otto B, Viehoff H, Koebnick C, Kohl A, Spranger J, Pfeiffer AF: Cereal fiber improves whole-body insulin sensitivity in overweight and obese women. Diabetes Care 2006, 29:775-780.

6. Jiang J, Qiu H, Zhao G, Zhou Y, Zhang Z, Zhang H, Jiang Q, Sun Q, Wu H, Yang L, et al: Dietary fiber intake is associated with $\mathrm{HbA1c}$ level among prevalent patients with type 2 diabetes in Pudong New Area of Shanghai. China. PLoS One 2012, 7:e46552.

7. Zhou BF, Stamler J, Dennis B, Moag-Stahlberg A, Okuda N, Robertson C, Zhao L, Chan Q, Elliott P, Group IR: Nutrient intakes of middle-aged men and women in China, Japan, United Kingdom, and United States in the late 1990s: the INTERMAP study. J Hum Hypertens 2003, 17:623-630.

8. Kaczmarczyk MM, Miller MJ, Freund GG: The health benefits of dietary fiber: beyond the usual suspects of type 2 diabetes mellitus, cardiovascular disease and colon cancer. Metabolism 2012, 61:1058-1066. 
9. Wheeler ML, Dunbar SA, Jaacks LM, Karmally W, Mayer-Davis EJ, Wylie-Rosett J, Yancy WS Jr: Macronutrients, food groups, and eating patterns in the management of diabetes: a systematic review of the literature, 2010. Diabetes Care 2012, 35:434-445.

10. Steemburgo T, Dall'Alba V, Almeida JC, Zelmanovitz T, Gross JL, De Azevedo $\mathrm{MJ}$ : Intake of soluble fibers has a protective role for the presence of metabolic syndrome in patients with type 2 diabetes. Eur J Clin Nutr 2009, 63:127-133.

11. Evert AB, Boucher $J$, Cypress M, Dunbar SA, Franz MJ, Mayer-Davis EJ, Neumiller JJ, Nwankwo R, Verdi CL, Urbanski P, Yancy WS: Nutrition therapy recommendations for the management of adults with diabetes. Diabetes Care 2013, 36:3821-3842.

12. Qi L, van Dam RM, Liu S, Franz M, Mantzoros C, Hu FB: Whole-grain, bran, and cereal fiber intakes and markers of systemic inflammation in diabetic women. Diabetes Care 2006, 29:207-211.

13. He M, van Dam RM, Rimm E, Hu FB, Qi L: Whole-grain, cereal fiber, bran, and germ intake and the risks of all-cause and cardiovascular disease-specific mortality among women with type 2 diabetes mellitus. Circulation 2010, 121:2162-2168.

14. Schoenaker DA, Toeller M, Chaturvedi N, Fuller JH, Soedamah-Muthu SS, Group EPCS: Dietary saturated fat and fibre and risk of cardiovascular disease and all-cause mortality among type 1 diabetic patients: the EURODIAB prospective complications study. Diabetologia 2012, 55:2132-2141.

15. Hopping BN, Erber E, Grandinetti A, Verheus M, Kolonel LN, Maskarinec G: Dietary fiber, magnesium, and glycemic load alter risk of type 2 diabetes in a multiethnic cohort in Hawaii. J Nutr 2010, 140:68-74.

16. Fukuda S, Saito H, Nakaji S, Yamada M, Ebine N, Tsushima E, Oka E, Kumeta K, Tsukamoto T, Tokunaga S: Pattern of dietary fiber intake among the Japanese general population. Eur J Clin Nutr 2007, 61:99-103.

17. Eshak ES, Iso H, Date C, Kikuchi S, Watanabe Y, Wada Y, Wakai K, Tamakoshi A, Group JS: Dietary fiber intake is associated with reduced risk of mortality from cardiovascular disease among Japanese men and women. J Nutr 2010, 140:1445-1453.

18. Kokubo $Y$, Iso H, Saito I, Yamagishi K, Ishihara J, Inoue M, Tsugane S, Group JS: Dietary fiber intake and risk of cardiovascular disease in the Japanese population: the Japan public health center-based study cohort. Eur J Clin Nutr 2011, 65:1233-1241.

19. Ohkuma T, Fujii H, Iwase M, Kikuchi $Y$, Ogata S, Idewaki $Y$, Ide H, Doi $Y$, Hirakawa $Y$, Mukai $N$, et al: Impact of eating rate on obesity and cardiovascular risk factors according to glucose tolerance status: the Fukuoka diabetes registry and the Hisayama study. Diabetologia 2013, 56:70-77.

20. Kobayashi S, Murakami K, Sasaki S, Okubo H, Hirota N, Notsu A, Fukui M, Date C: Comparison of relative validity of food group intakes estimated by comprehensive and brief-type self-administered diet history questionnaires against 16 d dietary records in Japanese adults. Public Health Nutr 2011, 14:1200-1211.

21. Science and Technology Agency: Standard tables of food composition in Japan (in Japanese. 5th edition. Tokyo: Printing Bureau of the Ministry of Finance; 2005

22. Kobayashi S, Honda S, Murakami K, Sasaki S, Okubo H, Hirota N, Notsu A, Fukui M, Date C: Both comprehensive and brief self-administered diet history questionnaires satisfactorily rank nutrient Intakes in Japanese adults. J Epidemiol 2012, 22:151-159.

23. Examination Committee of Criteria for Obesity Disease in Japan, Japan Society for the Study of Obesity: New criteria for obesity disease in Japan. Circ J 2002, 66:987-992.

24. Ainsworth BE, Haskell WL, Whitt MC, Irwin ML, Swartz AM, Strath SJ, O'Brien WL, Bassett DR Jr, Schmitz KH, Emplaincourt PO, et al: Compendium of physical activities: an update of activity codes and MET intensities. Med Sci Sports Exerc 2000, 32:S498-S504.

25. Matsuo S, Imai E, Horio M, Yasuda Y, Tomita K, Nitta K, Yamagata K, Tomino Y, Yokoyama H, Hishida A, Collaborators developing the Japanese equation for estimated GFR: Revised equations for estimated GFR from serum creatinine in Japan. Am J Kidney Dis 2009, 53:982-992.

26. Wallace TM, Levy JC, Matthews DR: Use and abuse of HOMA modeling. Diabetes Care 2004, 27:1487-1495

27. Levey AS, De Jong PE, Coresh J, El Nahas M, Astor BC, Matsushita K, Gansevoort RT, Kasiske BL, Eckardt KU: The definition, classification, and prognosis of chronic kidney disease: a KDIGO controversies conference report. Kidney Int 2011, 80:17-28.
28. Alberti KG, Eckel RH, Grundy SM, Zimmet PZ, Cleeman Jl, Donato KA Fruchart JC, James WP, Loria CM, Smith SC Jr, et al: Harmonizing the metabolic syndrome: a joint interim statement of the International diabetes federation task force on epidemiology and prevention; National heart, lung, and blood institute; American heart association; World heart federation; International atherosclerosis society; and International association for the study of obesity. Circulation 2009, 120:1640-1645.

29. Radloff LS: The CES-D scale: a self-report depression scale for research in the general population. Appl Psychol Meas 1977, 1:385-401.

30. Bodinham CL, Smith L, Wright J, Frost GS, Robertson MD: Dietary fibre improves first-phase insulin secretion in overweight individuals. PLoS One 2012, 7:e40834.

31. Wong JM, De Souza R, Kendall CW, Emam A, Jenkins DJ: Colonic health: fermentation and short chain fatty acids. J Clin Gastroenterol 2006, 40:235-243.

32. Freeland KR, Wilson C, Wolever TM: Adaptation of colonic fermentation and glucagon-like peptide-1 secretion with increased wheat fibre intake for 1 year in hyperinsulinaemic human subjects. Br J Nutr 2010, 103:82-90.

33. Kumar V, Sinha AK, Makkar HP, de Boeck G, Becker K: Dietary roles of non-starch polysaccharides in human nutrition: a review. Crit Rev Food Sci Nutr 2012, 52:899-935

34. McKeown NM, Meigs JB, Liu S, Saltzman E, Wilson PW, Jacques PF: Carbohydrate nutrition, insulin resistance, and the prevalence of the metabolic syndrome in the Framingham offspring cohort. Diabetes Care 2004, 27:538-546.

35. Otsuka R, Imai T, Kato Y, Ando F, Shimokata H: Relationship between number of metabolic syndrome components and dietary factors in middle-aged and elderly Japanese subjects. Hypertens Res 2010, 33:548-554.

36. Streppel MT, Arends LR, van't Veer P, Grobbee DE, Geleijnse JM: Dietary fiber and blood pressure: a meta-analysis of randomized placebo-controlled trials. Arch Intern Med 2005, 165:150-156.

37. Whelton SP, Hyre AD, Pedersen B, Yi Y, Whelton PK, He J: Effect of dietary fiber intake on blood pressure: a meta-analysis of randomized, controlled clinical trials. J Hypertens 2005, 23:475-481.

38. Jenkins DJ, Kendall CW, Augustin LS, Mitchell S, Sahye-Pudaruth S, Blanco Mejia S, Chiavaroli L, Mirrahimi A, Ireland C, Bashyam B, et al: Effect of legumes as part of a low glycemic index diet on glycemic control and cardiovascular risk factors in type 2 diabetes mellitus: a randomized controlled trial. Arch Intern Med 2012, 172:1653-1660.

39. Silva FM, Steemburgo T, de Mello VD, Tonding SF, Gross JL, Azevedo MJ: High dietary glycemic index and low fiber content are associated with metabolic syndrome in patients with type 2 diabetes. J Am Coll Nutr 2011, 30:141-148.

40. Katcher HI, Legro RS, Kunselman AR, Gillies PJ, Demers LM, Bagshaw DM, Kris-Etherton PM: The effects of a whole grain-enriched hypocaloric diet on cardiovascular disease risk factors in men and women with metabolic syndrome. Am J Clin Nutr 2008, 87:79-90.

41. McKeown NM, Yoshida M, Shea MK, Jacques PF, Lichtenstein AH, Rogers G, Booth SL, Saltzman E: Whole-grain intake and cereal fiber are associated with lower abdominal adiposity in older adults. J Nutr 2009, 139:1950-1955.

42. Du H, Der AD V, Boshuizen HC, Forouhi NG, Wareham NJ, Halkjaer J, Tjonneland A, Overvad K, Jakobsen MU, Boeing $H$, et al: Dietary fiber and subsequent changes in body weight and waist circumference in European men and women. Am J Clin Nutr 2010, 91:329-336.

43. Krishnamurthy VM, Wei G, Baird BC, Murtaugh M, Chonchol MB, Raphael KL, Greene T, Beddhu S: High dietary fiber intake is associated with decreased inflammation and all-cause mortality in patients with chronic kidney disease. Kidney Int 2012, 81:300-306.

44. Nakaji S, Sugawara K, Saito D, Yoshioka Y, MacAuley D, Bradley T, Kernohan $\mathrm{G}$, Baxter D: Trends in dietary fiber intake in Japan over the last century. Eur J Nutr 2002, 41:222-227.

45. Ministry of Health, Labour and Welfare: Dietary Reference Intakes for Japanese 2010: the summary report from the Scientific Committee of "Dietary Reference intakes for Japanese". http://www0.nih.go.jp/eiken/ info/pdf/dris2010en2.pdf

46. U.S. Department of Agriculture and U.S. Department of Health and Human Services: Dietary Guidelines for Americans, 2010. 7th edition. Washington, DC: U.S. Government Printing Office; 2010.

doi:10.1186/1475-2891-12-159

Cite this article as: Fujii et al:: Impact of dietary fiber intake on glycemic control, cardiovascular risk factors and chronic kidney disease in Japanese patients with type 2 diabetes mellitus: the Fukuoka Diabetes Registry. Nutrition Journal 2013 12:159. 